\title{
Vocational Program Completion
}

National Cancer Institute

\section{Source}

National Cancer Institute. Vocational Program Completion. NCI Thesaurus. Code C67141.

Indicates that a person has attended or received a degree from an occupational, technical, or vocational program as their highest level of educational achievement. 